\title{
From Pre-Defined to Open-Ended Projects: Evaluating First-Year Ability to Innovate and Problem Solve
}

\section{Kaylee A. Dunnigan, NYU Tandon School of Engineering}

Kaylee Dunnigan is a third-year undergraduate student working towards her B.S. in Chemical and Biomolecular Engineering at the NYU Tandon School of Engineering. She is the deputy head of research and development for the Introduction to Engineering and Design at Tandon. She helps develop semester long design projects for students, hands-on labs, as well as mentor students throughout these projects. She has worked previously at Sandia National Labs Advanced Materials Labs and the University of New Mexico as a research intern. Currently she is a research assistant for the Modestino Group at NYU Tandon helping develop and optimize a new type of process system for Nylon 6,6. She is the President of the NYU chapter of Society of Advanced Materials Science and Process Engineering and is the composites lead for the NYU baja competition team.

\section{Dr. Jack Bringardner, NYU Tandon School of Engineering}

Jack Bringardner is an Assistant Professor in the General Engineering Department and Civil Engineering Department at NYU Tandon School of Engineering. He teaches the First-Year Engineering Program course Introduction to Engineering and Design. He is also the Director of Vertically Integrated Projects at NYU. His Vertically Integrated Projects course is on Smart Cities Technology with a focus on transportation. His primary focus is developing curriculum, mentoring students, and engineering education research, particularly for project-based curriculum, first-year engineering, and transportation. He is active in the American Society for Engineering Education and is the Webmaster for the ASEE First-Year Programs Division and the First-Year Engineering Experience Conference. He is affiliated with the Transportation Engineering program in the NYU Civil and Urban Engineering Department, and is the Associate Director for Education and Workforce Development Initiatives for the Connected Cities for Smart Mobility Towards Resilient Transportation Tier I USDOT University Transportation Center. He is the advisor for NYU student chapter of the Institute for Transportation Engineers.

\section{Prof. Gunter W. Georgi, NYU Tandon School of Engineering}

Gunter W. Georgi, a registered Professional Engineer, is an Industry Professor at the New York University Tandon School of Engineering in Brooklyn, New York. Prof. Georgi is the course director for the Introduction to Engineering and Design course. He received his B.S. from Cooper Union and his M.S. and professional M.E. degrees from Columbia University. He has worked many years in the aerospace industry in design, analysis, and management functions. His most challenging task was the responsibility for the Thermal Mission Analysis of the Lunar Module from Project Apollo. 


\title{
From Pre-Defined to Open-Ended Projects: Evaluating First-Year Ability to Innovate and Problem Solve
}

\begin{abstract}
This complete evidence-based practice paper describes NYU Tandon School of Engineering's first-year engineering course that has increased the proportion of open-ended projects to predefined projects being offered. This course teaches 320 students per semester with multidisciplinary labs and hands-on projects as the center of the course. Pilots for these projects were offered in Fall 2016, Spring 2017, Fall 2017 and Spring 2018 to about 15 students for Fall 2016 and Spring 2017 and about 30 students for the last two sessions. Positive feedback from students prompted further expansion, to 50 students, in Fall 2018 and a greater diversity of topics. There were three types of projects formulated based on the pilot sections: free-choice open-ended projects (free-choice OEP), prompt-based open-ended projects (prompt-based OEP), and predefined projects.
\end{abstract}

The free-choice OEPs allow students to propose a real-world problem they are interested in solving and develop a physical prototype throughout the semester. A more structured version of this project is the prompt-based OEP, where faculty, independent of their association with the course or within the course, provide prompts for students to develop ideas into working prototypes. The most structured projects are the predefined project choices which are projects with set goals and tasks. In Fall 2018, 13 groups participated in free-choice OEP projects, 2 groups in piloted prompt-based OEP projects, and the rest of the groups took part in predefined projects. The curriculum makes the students familiar with the engineering design process, computer-aided design (CAD), Arduino programming, prototyping, product development, and the integration of teamwork and project management.

This study examined the feedback from an end of the semester survey of 226 first-year students to evaluate their capabilities, preparedness, and interest in the project options. The results show that the split of students whose first choice would be free-choice, prompt-based, and predefined OEPs is $38 \%, 26 \%$, and $36 \%$ respectively. This finding is in contrast to previous studies which found that free-choice open-ended projects were appropriate for 5-15\% of firstyear students. Students who participated in predefined projects were more dissatisfied with their project choice and students who participated in open ended projects were more likely to want to continue working on their projects in the future based on statistically significant differences in survey responses. Students who participated in free-choice OEPs were also more interested in being a part of new projects in the future.

\section{Introduction}

Academic projects are integrated into courses to offer students a hands-on learning experience. Many first-year engineering courses at schools like Northwestern University, California Polytechnic State, and University of St. Thomas have predefined projects in their firstyear curriculum [1-3]. These projects' goals are to develop fully functional prototypes that can complete specific sets of tasks and meet certain requirements. This allows for the difficulty level between projects to remain the same and provides a clear grading system for the prototypes. 
Another form of projects available throughout engineering curriculum are open-ended projects (OEPs). OEPs have fewer restrictions and require the development of a unique, working prototype through brainstorming and iterative design. It requires students to develop a problem statement of their own. Students evaluate global, personal, ecological, social, technological, and other diverse sets of problems to determine the focus of their project. Students are required to create a working prototype, though it is not expected to be as fully functional as the predefined projects. The final product is a realistic solution that can be described as marketable, manufacturable, and applicable.

At NYU Tandon School of Engineering two types of OEPs are being explored for firstyear curriculum. In the Fall of 2018, 13 groups, an increase from the 6 from previous semesters, participated in free-choice open-ended design projects where students were tasked with generating their own problem, solution, and prototype throughout the semester with the assistance of an undergraduate mentor. These ideas were submitted and reviewed for feasibility before being approved [4]. The second type of OEP, piloted in Fall 2018, was prompt-based open ended projects which allowed students to develop their own solutions for problem statements generated by school faculty. These projects were offered as an alternative to predefined projects which included Lego Mindstorms robotics, the computer-aided design (CAD) of a building, and a coding based nano-robotics challenge.

OEPs offer students more agency over their project which leads to intrinsic motivation and desire to contribute to more innovative projects in the future [1]. Various types of demanding projects, such as open-ended projects, are offered at universities alongside predefined projects [5]. So at NYU Tandon School of Engineering this study was carried out with the focus to determine the quantity and type of OEPs that should offered. Another focus of this study was to evaluate the optimal structure of OEPs in a first-year program.

\section{Literature Review}

Many first-year programs have looked at the challenges and logistics behind open-ended styled projects and the impact that they have on students and the course. One of these issues is ensuring that the first-year curriculum offers an introduction to a variety of engineering-based skill sets, so that by the end of the course students have gained useful skills. Another goal is to keep students interested in engineering curriculum by making projects more rewarding and develop projects that have a lasting positive impact.

Various forms of OEPs, projects where students have the opportunity to freely choose the project topics, design, and pivot the project concept, have received feedback through surveys that suggest students who participate in OEPs have a greater enjoyment of the course and the students feel like they learn more [6-8]. Structuring OEPs to allow for students to choose the project topic, application, providing them with basic materials, and giving students in class time to work on their project can support the students chance of success in their projects [6-8]. This supports that students can benefit from more material and educational recourses when developing their OEPs. So to ensure student success, students need to be provided with enough educational materials to confidently work on and complete their projects, regardless of how open-ended the project is. One way of providing ample recourses is developing specialized kits as seen with 
similar courses [9]. If students are not provided with enough resources to properly and confidently tackle open-ended problems than they will not focus on the learning objective of the process of product development and will instead only be thinking about the end goal [10]. Other courses have first years learn to design in Computer Aided Design (CAD) software and 3D print during the course [11]. Based on these studies in this first year engineering course students are provided with an upper-classman mentor, in class time to work on their projects, a basic kit of materials, non-mandatory workshops, a 3D-printing shop only for the students in the course, and $\$ 100$ stipend to use to develop their project further.

Certain educational topics have been deemed a core part of the curriculum throughout engineering programs, including: iterative prototyping, computer aided design, 3D printing, programming, and professional skills such as oral and written communication [3,9,12]. This first year program is develop OEPs to help further integrate their learning objectives seamlessly into the curriculum. Universities have also shown that more intense and academically rich high-level projects in the first-year help students take higher level courses earlier on, students can develop skills that can last them throughout their lives, and the project experience help them receive competitive internships $[5,13]$. Courses that focus on innovation and novel product development have had success in encouraging their students to be more interested in entrepreneurship and innovation $[1,2,14]$. So, [this first year program] aims to provide students with a high-level academic project during one of their first semester to provide them with valuable hands on experience that can help them pursue future academic projects and be qualified for competitive internships, both with the end goal of improving their undergraduate career. Students participating in predefined projects do not require as many resources to build their project, but potentially do not get as much long term out of the course.

Other first year design courses recommend that students are given OEP and predefined project opportunities, but for the OEP to be successful the students need to be provided with more structure and guidelines to help them through difficult decision making while developing their project [8]. These guidelines need to be set from the very beginning of the design process as students have been shown to develop too complex design ideas that cannot be completed within the resources provided by the course and the time limits which is not an issue for predefined projects where students can better conceptualize their product [10]. Courses combat this issue by providing students a range of open-ended projects to choose from [7]. In [this course] to better help students through this decision making and design issues each group is given the opportunity to work with an upper-class teaching assistant who they meet with weekly to asses what the students need, where they are in their project, and whether or not their project needs to be pivoted to better meet deadlines of the course.

Other engineering courses that provide OEPs have shown that only a small percentage of students have expressed interest and capability in participating in free-choice open ended projects over predefined projects, around 5-15\% [4,8]. If students do enjoy these OEP and they are having a large impact on the students' curriculum there could possibly be barriers that are limiting all students from being able to participate in these beneficial projects. In this study students were given two main project types, a list of predefined project topics and an option to come up with their own project idea based on the materials provided. 


\section{Methods}

The number of open-ended design projects was increased from 5 to 15 from Spring 2018 to Fall 2018. In Spring 2018, free-choice OEP was the only open-ended design project offered. Two prompt-based OEPs were added for the fall semester: an underwater autonomous vehicle and a drone. The course also offered three predefined projects in Lego robotics, python programming, and CAD modeling. Both free-choice and prompt-base groups were given the ability to pivot, develop, and build their prototypes as they saw fit. These projects introduced and taught students about current problems in Science, Technology, Engineering, and Math (STEM), and encouraged them to iterate through solutions. The program also provided students access to materials, mentors, technical skill workshops, and a stipend to buy new materials, alongside NYU Tandon School of Engineering's Makerspace. In the Fall of 2018, the students' stipend was $\$ 100$ for each project and all materials were approved for purchase by the mentor and faculty. Information about the projects, the course structure, and the goals of the course are introduced to students during their first recitation and during the first lecture, a professor and an upper-class teaching assistant work together to introduce the course and the projects to the students during both of these periods.

At the start of the semester, an application was sent out to first-year students enrolled in the course. They were encouraged to apply through email and during class presentations. The faculty and student course leaders determined the most feasible projects that could be completed within the time and cost constraints. These projects were then matched with a mentor from upper-class teaching assistants based on their own experience with those topics. During the second- or third-week students select a project to participate in during their recitation section forming groups of 2-4 students. At this recitation, if there is a student who was approved to participate in an OEP, then the student will pitch the project to the class then 1-3 interested students can join the team. There was a maximum of 2 OEPs per recitation section to ensure there was enough interest to form teams. All other students would then form groups and chose a predefined project from the options available, with no more than one group on a predefined project per section. Students are highly encouraged to form interdisciplinary teams to improve the engineering design process by incorporating different major perspectives, though some recitation sections have a high density of one major.

A basic kit was provided to each group which consisted of a microcontroller, breadboard, wires, and some commonly used sensors. Supplemental common materials and sensors were available upon request. Students used their stipend to order all other materials, but restrictions such as deadlines for orders were put on the purchases.

The students were tasked with writing a report to describe their semester plan for their project with a schedule, cost estimates, and initial design ideas as an initial deliverable for the project. While this report is completed by the third week of class and a lot of their initial plan is subject to change, it acted as an initial layout of their project. Following the outline of the predefined projects, the OEPs also had three deliverables which were due at week 6, 9, and 11 of the course. Whereas the predefined projects have preset benchmarks depending on the project, for open ended projects the benchmark requirements are set by the mentor and reviewed by faculty. The students participating in open-ended projects write a final report detailing out their 
whole project, including cost, technical descriptions, and descriptions of their projects importance, at the end of the semester.

A survey was sent out at the end of the semester to all students in the course to gather their opinions on the projects they worked on, the course curriculum, and gauge their interest in the other available types of projects. This survey included quantitative and qualitative responses that will be discussed in later sections. The full survey can be found in the appendix.

The survey's main focus was asking students to retrospectively consider what project would they have preferred from the three listed options (free-choice open-ended project, promptbased open-ended project, and predefined project) and why. The survey asked students what skills they found the most valuable in their project and what they liked and didn't like about their experience. A total of 226 student responses were received.

\section{Analysis}

Over the Fall 2016, Spring 2017, Fall 2017, and Spring 2018 a special section of the course was ran where students would participate in free-choice OEP with 15 students in the first two semesters and about 30 students in the second two. This course option ended and shifted into a project choice that students could apply for and complete instead of the pre-defined projects; these projects were free-choice OEPs. Five of these projects were offered in Spring 2018 and 13 in the Fall of 2018. Alongside free-choice OEP in Fall 2018 two prompt-based OEPs were offered. The regular semester long design projects that students participated in are predefined projects that are based in Lego-robotics, coding, and computer-aided design. All groups had two to four students.

In total 226 responses were gathered. 30 of these responses are from free-choice OEP groups, 188 from predefined projects, and 8 from students who participated in a prompt-based OEP. Due to prompt-based OEPs being piloted, they only had a few responses and were not analyzed quantitatively.

\section{Example Fall 2018 Projects}

All OEPs participated in a presentation competition at the end of the semester to showcase their project. Each member of the top two teams won an award of $\$ 200$ for their efforts. Predefined projects also compete in a separate competition so that those students have a similar incentive for not just completing their project but to go above and beyond in creativity and work ethic. The first OEP team was "PepperPet," a holographic digital pet that acts as a talking companion. The team designed all the pets themselves and used a free API to help generate the animation from the static images. These images would be displayed based on how the user interacted with the display and buttons. 


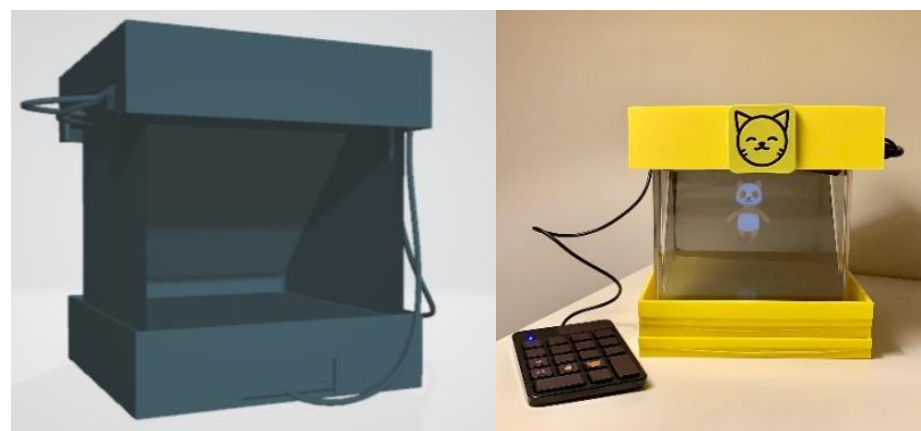

Figure 1: CAD Drawing and Final Build of the "PepperPet" Case

The other winning team, "SpeakSign," developed a software, glove, and remote that converts sign language into text and voice. This would enable someone who used American Sign Language (ASL) to communicate to someone who didn't understand sign language. This group developed a program to recognize the colors on the gloves using an open source computer vision library; each color represented a different finger. By using color locations to calculate finger distances, they matched the finger placement to an ASL dictionary. The dictionary provided the information about corresponding finger distances to letters. The remote was used to start the program, stop it, and add a space between words. The student who developed the original idea was inspired by a friend who expressed difficulty communicating with a family member.

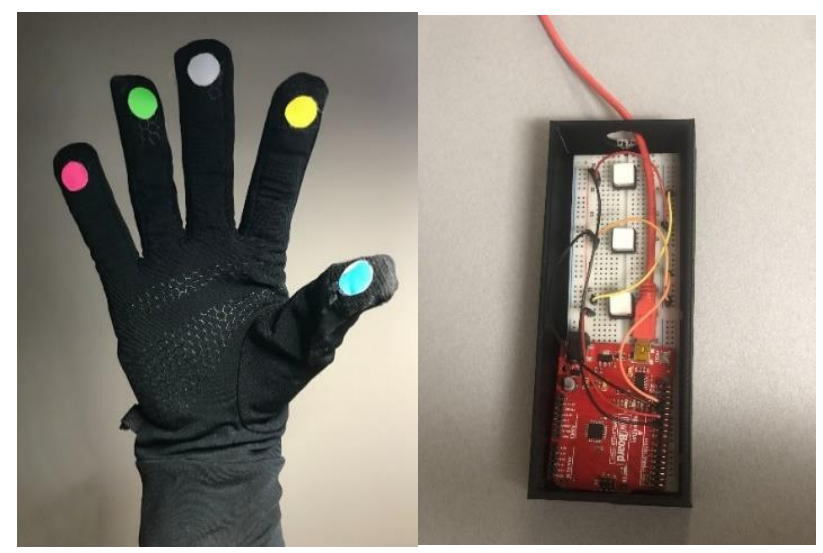

Figure 2: "SpeakSign" Glove and Remote

Two second place projects were selected and awarded \$50 per team member for their efforts. One of the groups, "Ojo," developed augmented reality software that converted text into a dyslexia friendly font using a smartphone. They connected their phone to 3D-printed 'glasses' that displayed and converted the text.

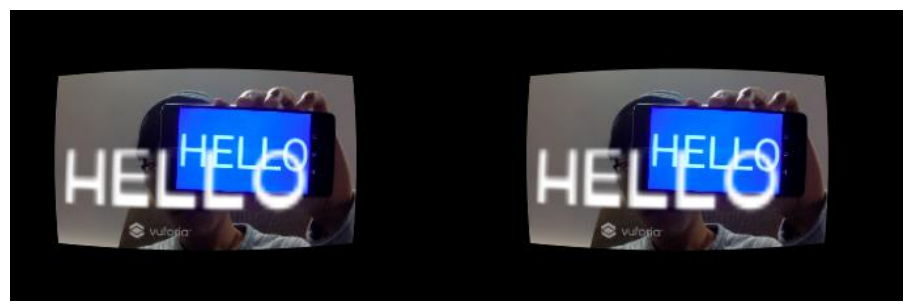

Figure 3: Dyslexia Friendly Font Displayed Over Text 
The other second place group, "Helping Hand," designed and developed a prosthetic arm that incorporated a series of Arduino servo motors that were controlled by a muscle sensor. This enabled the prosthetic to pick up lightweight objects. Their goal was to make an inexpensive, user-controlled prosthetic.

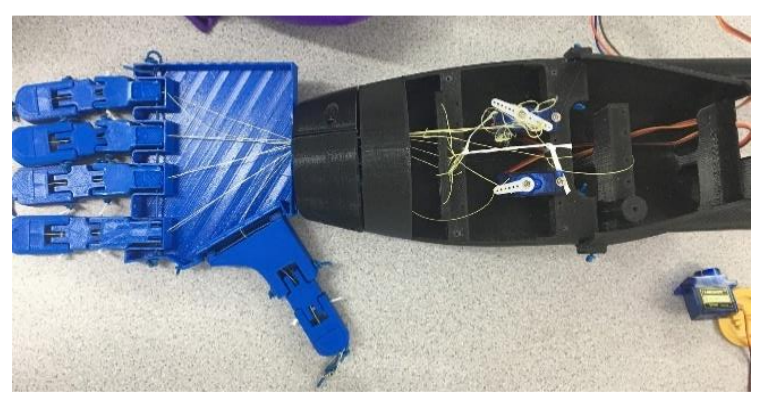

Figure 4: Final 3D Printed Prosthetic Hand

\section{Survey Results}

The survey was composed of questions about aspects of the project and the course using a 5-point Likert scale. Students were also provided with a description of each project type asked to theoretically reconsider the project choice made at the start of the semester. Responses are sorted by project type. The paper also includes short answer questions to gain a more thorough understanding of their responses. Free-choice OEPs $(n=30)$ and predefined projects $(n=188)$ were analyzed qualitatively and quantitatively while the prompt-based OEP data was reviewed qualitatively due to a small sample size $(n=8)$.

\section{Overall Project Preference}

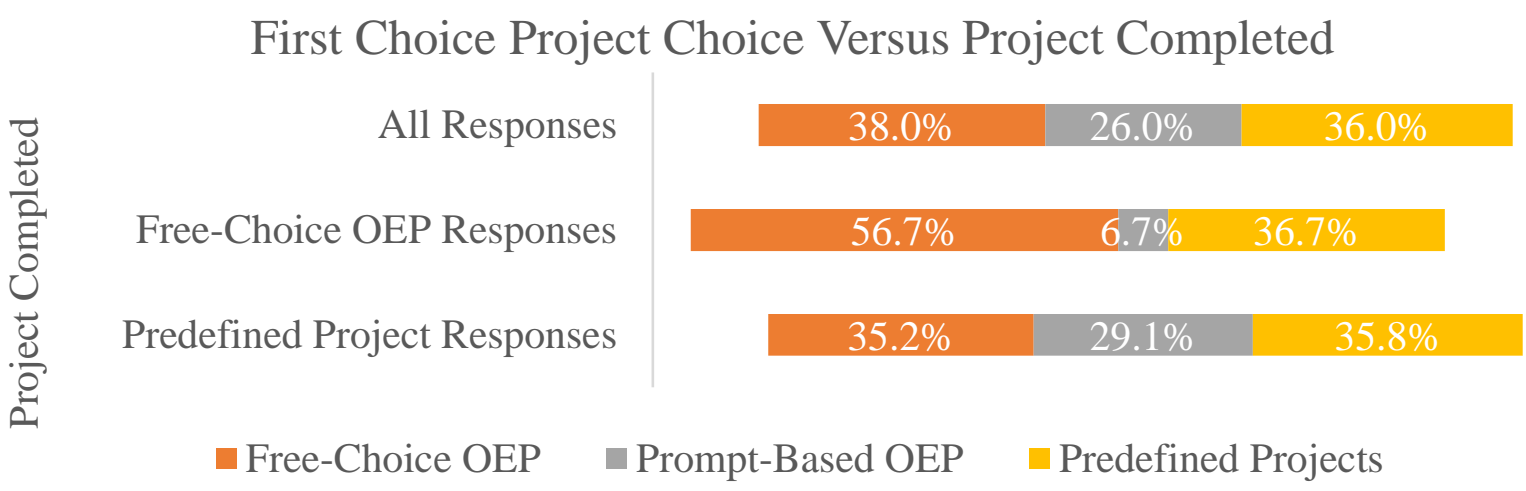

Figure 5: Stated Project Preference for All Students and Students from Each Project Type

Students were asked to rank their project preference, these answers are listed by project type participated in, displayed in Figure 5. Regardless of the project participated in, each grouping had about $64 \%$ of students preferring one of the OEP types. 
Project Perspectives Where Responses Differed

Table 1: Statistically Significant Difference Between Student Project Type

\begin{tabular}{|l|c|c|c|c|c|}
\hline \multicolumn{1}{|c|}{ Question } & $\begin{array}{c}\text { Free-Choice OEP } \\
\text { Response Mean }\end{array}$ & $\begin{array}{c}\text { Predefined Project } \\
\text { Response Mean }\end{array}$ & $\mathrm{df}$ & $\begin{array}{c}\mathrm{t} \text { Critical } \\
\text { two-tail }\end{array}$ & $\begin{array}{c}\mathrm{P}(\mathrm{T}<=\mathrm{t}) \\
\text { two-tail }\end{array}$ \\
\hline $\begin{array}{l}\text { I was dissatisfied with my } \\
\text { project selection. }\end{array}$ & 2.10 & 2.65 & 37 & 2.03 & 0.03 \\
\hline $\begin{array}{l}\text { I plan to continue working } \\
\text { on the product. }\end{array}$ & 3.37 & 2.49 & 41 & 2.02 & $1.70 \mathrm{E}-04$ \\
\hline $\begin{array}{l}\text { I am interested in creating } \\
\text { another product. }\end{array}$ & 4.17 & 3.62 & 48 & 2.01 & $1.42 \mathrm{E}-03$ \\
\hline $\begin{array}{l}\text { I am interested in working to } \\
\text { change a product. }\end{array}$ & 4.03 & 3.61 & 44 & 2.02 & $4.81 \mathrm{E}-03$ \\
\hline
\end{tabular}

Table 1 isolates the students' responses from the 5-point Likert scale questions that were statistically different between students who participated in free-choice OEPs and predefined projects. The two-tailed t-test null hypothesis assumes that the difference between the two means is equal to zero. All t-tests completed on statements presented in Table 1 concluded a rejection of the null hypothesis, with a p-value smaller than alpha (alpha $=0.05$ ).

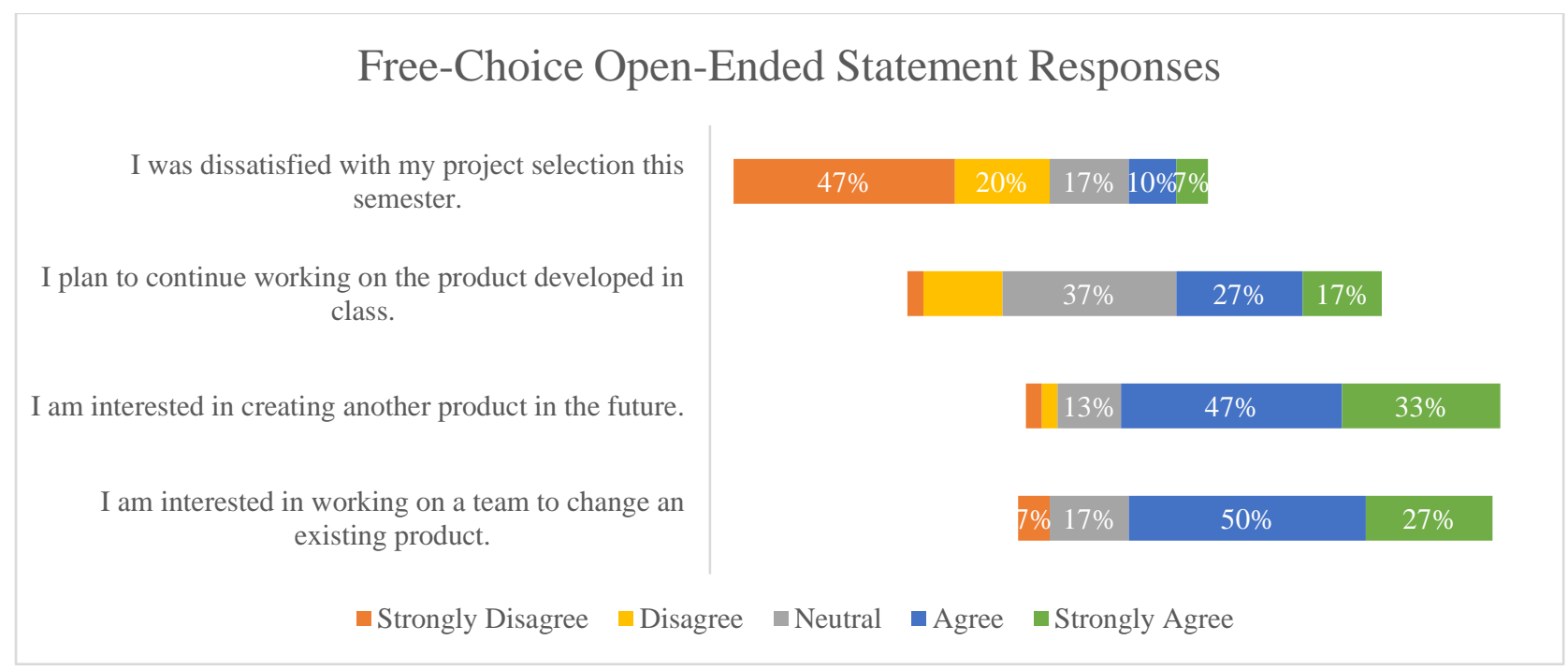

Figure 6: Likert Response Distribution for Students in Free-Choice Projects that Were Statistically Different from Students in Pre-Defined Projects 


\section{Predefined Project Statement Responses}

I was dissatisfied with my project selection this semester.

I plan to continue working on the product developed in class.

I am interested in creating another product in the future.

I am interested in working on a team to change an existing product.

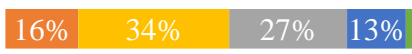

\begin{tabular}{l|l|l|l}
$24 \%$ & $28 \%$ & $29 \%$ & $14 \%$
\end{tabular}

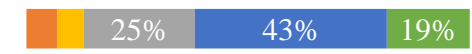

$26 \% \quad 43 \%$

$15 \%$

घtrongly Disagree $\square$ Disagree $\quad$ Neutral $\quad$ Agree $\quad$ Strongly Agree

Figure 7: Likert Response Distribution for Students in Pre-Defined Projects that were Statistically Different from Students in Free-Choice Projects

The distribution of responses in Figure 6 and 7 results suggest that students participating in a free-choice OEP project expressed more interest to work on product development in the future. This is true for their course project, changing existing products, and developing something completely new. Also, free-choice OEP students are less dissatisfied in their project selection.

\section{Sample Project Perspectives Where Responses Were Not Statistically Different}

Table 2: No Statistically Significant Difference Between Student Project Type

\begin{tabular}{|c|c|c|c|c|c|}
\hline Question & $\begin{array}{c}\text { Free-Choice } \\
\text { OEP Response } \\
\text { Mean }\end{array}$ & $\begin{array}{c}\text { Predefined } \\
\text { Project } \\
\text { Response Mean }\end{array}$ & df & $\begin{array}{l}\text { t Critical } \\
\text { two-tail }\end{array}$ & $\begin{array}{l}\mathrm{P}(\mathrm{T}<=\mathrm{t}) \\
\text { two-tail }\end{array}$ \\
\hline $\begin{array}{l}\text { I have enhanced my ability to design a system, } \\
\text { component, or process to meet desired needs. }\end{array}$ & 3.73 & 3.77 & 37 & 2.03 & 0.85 \\
\hline $\begin{array}{l}\text { The in-class exercises, such as programming, } \\
\text { working with breadboard circuits, fabrication } \\
\text { has decreased my motivation to study math, } \\
\text { physics and chemistry. }\end{array}$ & 2.67 & 2.96 & 50 & 2.01 & 0.10 \\
\hline I am proud of the product I created in class. & 3.81 & 3.62 & 38 & 2.02 & 0.50 \\
\hline
\end{tabular}

Table 2 isolates sample students' responses from the 5-point Likert scale questions that were not statistically different between students who participated in free-choice OEPs and predefined projects. The two-tailed t-test null hypothesis assumes that the difference between the two means is equal to zero. All t-tests completed on statements presented in table 2 did not conclude a rejection of the null hypothesis, with a $\mathrm{p}$-value not smaller than alpha (alpha=0.05). 


\section{Free-Choice OEP Statement Responses}

I have enhanced my ability to design a system, component, or process to meet desired needs.

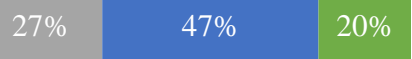

The in-class exercises, such as programming, working with breadboard circuits, fabrication has decreased my motivation to study math, physics and chemistry.

I am proud of the product I created in class.

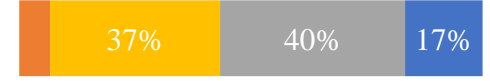

$\square$ Strongly Disagree $\quad$ Disagree $\quad$ Neutral $\quad$ Agree $\quad$ Strongly Agree

Figure 8: Sample Likert Response Distribution for Students in Free-Choice Projects that Were Not Statistically Different from Students in Pre-Defined Projects

\section{Predefined Project Statement Responses}

I have enhanced my ability to design a system, component, or process to meet desired needs.

The in-class exercises, such as programming, working with breadboard circuits, fabrication has decreased my motivation to study math, physics and chemistry.

I am proud of the product I created in class.

ఐ Strongly Disagree $\quad$ Disagree

\section{$21 \%$}

$49 \%$

$20 \%$
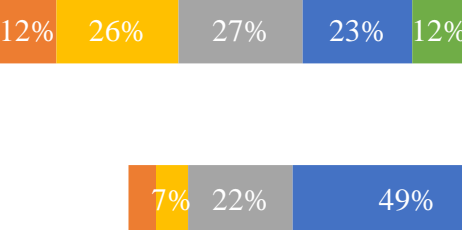

$16 \%$

Neutral

- Agree $\square$ Strongly Agree

Figure 9: Sample Likert Response Distribution for Students in Pre-Defined Projects that Were Not Statistically Different from Students in Free-Choice Projects

The select questions in Figure 8 and Figure 9 were hypothesized to have different responses based on project type. It was expected that the OEPs, that require the development of more complex problem solving and more engineering skill sets than the predefined projects, would significantly enhance students' ability and motivation in STEM fields. 
Table 3: Stated Ability to Complete Project Type Based on Preference, Experience, and Support

\begin{tabular}{|l|c|c|c|c|c|}
\hline \multicolumn{1}{|c|}{ Question } & $\begin{array}{c}\text { Free-Choice OEP } \\
\text { Response Mean }\end{array}$ & $\begin{array}{c}\text { Predefined } \\
\text { Project Mean }\end{array}$ & df & $\begin{array}{c}\text { t Critical } \\
\text { two-tail }\end{array}$ & $\begin{array}{c}\text { P(T<=t) } \\
\text { two-tail }\end{array}$ \\
\hline $\begin{array}{l}\text { I would have liked to participate in a } \\
\text { free-choice OEP during the duration of } \\
\text { this course. }\end{array}$ & $\mathbf{4 . 1 0}$ & $\mathbf{3 . 2 8}$ & $\mathbf{3 7}$ & $\mathbf{2 . 0 3}$ & $\mathbf{1 . 3 8 E - 0 3 *}$ \\
\hline $\begin{array}{l}\text { Without additional resources I would have } \\
\text { been able to complete a free-choice OEP } \\
\text { project. }\end{array}$ & 3.17 & 3.07 & 35 & 2.03 & 0.44 \\
\hline $\begin{array}{l}\text { With additional resources I would have } \\
\text { been able to complete a free-choice OEP } \\
\text { project. }\end{array}$ & 3.80 & 3.61 & 35 & 2.03 & 0.44 \\
\hline $\begin{array}{l}\text { I would have liked to participate in a } \\
\text { pre-defined project during the duration } \\
\text { of this course. }\end{array}$ & $\mathbf{2 . 9 3}$ & $\mathbf{3 . 4 8}$ & $\mathbf{3 5}$ & $\mathbf{2 . 0 3}$ & $\mathbf{0 . 0 2 *}$ \\
\hline $\begin{array}{l}\text { Without additional resources I feel like I } \\
\text { would have been able to complete a pre- } \\
\text { defined project. }\end{array}$ & 3.72 & 3.61 & 37 & 2.03 & 0.60 \\
\hline $\begin{array}{l}\text { With additional resources I would have } \\
\text { been able to complete an pre-defined } \\
\text { project. }\end{array}$ & 3.93 & 3.80 & 39 & 2.02 & 0.48 \\
\hline
\end{tabular}

*Statistically significant difference at 0.05 confidence level

All survey questions listed in Table 3 were analyzed with a two-tail t-test. For all these responses the null hypothesis was that the data sets of both groups are equivalent. The two-tailed $\mathrm{t}$-test null hypothesis assumes that the difference between the two means is equal to zero. All ttests completed on statements presented with a p-value not smaller than alpha (alpha $=0.05)$ so not conclude a rejection of the null hypothesis. All t-tests that have a p-value smaller than alpha $($ alpha $=0.05)$ have a rejection of the null hypothesis.

It has been shown that when students are given various types of project choices they show a biased preference towards the project in which they participated [8]. This bias is replicated in Table 3, where students are given the description of the project type, either the predefined project or OEP, they showed preference for the project that they had participated in. But both groups expressed similar confidence in being able to complete either project, free-choice OEPs or predefined projects, with the knowledge they had coming into the course and with the additional resources. 


\section{Qualitative responses}

Table 4-6 lists some representative responses from the students open-ended statements.

Table 4: Project Preference Qualitative Statements

Given the three available options (RAD, AGP, and Pre-defined Projects), describe which project(s) you would prefer and why.

1. I prefer something where there are a set of rules and principles that I would follow. I do not feel confident in creating anything because of my current lack of technical knowledge.

2. AGP [prompt-based OEP] because there is structure but also it is open ended.

3. RAD [free-choice OEP] because it gives the best relevant experience to creating, designing, and marketing a project.

The responses followed some basic trends seen in Table 4. Students who showed preference for pre-defined projects expressed feeling unprepared and lacking in skill to complete a more OEP or they felt that they needed the structure that pre-defined projects offered. Students whose first choice was free-choice OEPs explained that they would have liked a more complex project but liked that the provided idea would seem to help if they lacked creativity or previous engineering experience. Students whose first choice was free-choice OEPs expressed interest in developing their own idea and they would feel more invested if it was an idea they developed. Overall students who feel unprepared and unconfident in their abilities seem to feel more comfortable completing a prompt-based OEP or a predefined project.

Table 5: Biggest Challenges for the Project Qualitative Statements

What did you struggle with the most on your project?

1. Goal setting was the most difficult, as my team and I set goals that were too large and abstract.

2. Teamwork

3. Coming up with our way of narrowing the scope of our broad project topic.

4. I struggled in making decisions along with my group because it delayed our process in finishing the project.

5. I did a RAD [free-choice OEP] project, I had to do a lot of research and come up with an initial design with the first week or so. I would have liked to have a bit more help with that or at least a bit more direction from my TA.

The number one difficulty throughout the project, as summarized in Table 5, for students was teamwork and communication. Though they also expressed difficulty with decision making in terms of the large aspects of their projects both at the very beginning and throughout the semester.

Table 6: Most Enjoyable Part of Project Qualitative Statements

\section{What did you enjoy the most about your project (what shouldn't change)?}

1. The open-endedness and opportunity to learn new skills through workshops.

2. The creative aspect. I enjoyed being able to choose the layout and what I can and cannot do for the project.

3. The ability to work with a mentor who really helped build our ideas and process. 
Though the students also enjoyed, as summarized in Table 6, the open-ended aspects of some of their projects and having access to a mentor to help guide them through difficult aspects.

\section{Conclusions and Recommendations}

OEPs allow for students to gain an understanding of problem solving through developing their own technology. The data collected confirms that these OEPs make students want to participate in more innovative projects and product development in the future. The findings of this research suggest that $38 \%$ of all students would be interested in free-choice OEPs and $26 \%$ would be interested in prompt-based OEPs. Also regardless of project completed by the students, when given a variety of educational and faculty resources (such as a mentor, teaching assistants, workshops, and a stipend), were equally confident to be able to complete a free-choice OEP or a predefined project. This large percentage of student interests do not support previous findings that suggest only a small fraction, 5-15\%, of students are able to and interested in these projects. Along with this free-choice OEP students are significantly less dissatisfied with their semester long design project and are more encouraged to participate in projects in the future.

Taking all of this into consideration, the amount of OEPs offered from the Fall 2018 to Spring 2019 will scale up from about 20 percent to at least 33 percent, with a fifth of the openended projects to be offered as prompt-based. This will allow for prompt-based projects to further be piloted and offer more diversity in OEP types available in the course. Given the results of this study beyond the Spring 2019 semester, the program can further expand the amount of OEPs offered beyond 33 percent, since more than that amount of students expressed interest and ability. In the future, students could be tracked as they go through their next three years of their undergraduate education in order to determine if one type of first-year design project resulted in students participating more in projects throughout their engineering education.

Prompt-based OEPs should have some specificity in the project type, and even though students are allowed to pivot the initial idea, they expressed confusion on being given a prompt that is too open-ended. All free-choice OEPs need to be reviewed based on the criteria that it can be completed by any first-year student with the provided resources in the course of a semester. Other first-year design based courses could further expand their project options focusing more on innovative projects and the process of design thinking as opposed to predefined projects. These projects require an involved and dedicated mentor and ample staff and resources to help all students regardless of their background. These projects also require additional training of teaching assistants alongside a budget for inventory and student stipends for purchasing equipment.

Scaling up requires certain logistical considerations to be determined so that all students, regardless of their background in STEM, will continue to develop quality projects. Projects should be selected, and prompts developed, based on the ability for a first year to complete the project over a semester and with a relatively small budget. Mentors should be paired with a team based on the mentor's experience and ability with the team's project. TAs who help the students need more microcontrollers training to better assist the students as they develop their projects. More deadlines, such as specific times and dates to complete purchases, need to be planned in advance to create a smoother process. While mentors determine the tasks that groups need to 
complete by three sets of milestones, these tasks need to be approved by a second party to make sure all groups are being held up to a similar standard of difficulty.

\section{References}

[1] Riofrío, J. A., \& Gettens, R., \& Santamaria, A. D., \& Keyser, T. K., \& Musiak, R. E., \& Spotts, H. E. (2015, June), Innovation to Entrepreneurship in the First Year Engineering Experience Paper presented at 2015 ASEE Annual Conference \& Exposition, Seattle, Washington. 10.18260/p.24306

[2] Gerhart, A., "Campus-wide Course Modification Program to Implement Active \& Collaborative Learning and Problem-based Learning to Address the Entrepreneurial Mindset", 2013 ASEE Annual Conference and Exposition, June 23-26, Atlanta, GA.

[3] Recktenwald, G. W., \& Hall, D. E. (2011, June), Using Arduino as a platform for programming, design and measurement in a freshman engineering course Paper presented at 2011 ASEE Annual Conference \& Exposition, Vancouver, BC. https://peer.asee.org/18720

[4] Bringardner, J., \& Georgi, G. W., \& Bill, V. (2017, August), Examples of Free Choice OpenEnded Design Projects in a First-Year Engineering Course Paper presented at 2017 FYEE Conference, Daytona Beach, Florida. https://peer.asee.org/29409

[5] Freeman, S. F., \& Pfluger, C., \& Whalen, R., \& Schulte Grahame, K., \& Hertz, J. L., \& Variawa, C., \& Love, J. O., \& Sivak, M. L., \& Maheswaran, B. (2016, June), Cranking Up Cornerstone: Lessons Learned from Implementing a Pilot with First-Year Engineering Students Paper presented at 2016 ASEE Annual Conference \& Exposition, New Orleans, Louisiana. 10.18260/p.26595

[6] Shepard, T. (2013, June), Implementing First Year Design Projects with the Power of Choice. Paper presented at 2013 ASEE Annual Conference, Atlanta, Georgia, http://peer.asee.org/19722

[7] Meadows, L.A., \& Fowler, R., \& Hildinger, E.S. (2012, June), Empowering Students with Choice in the First Year. Paper presented at 2012 ASEE Annual Conference, San Antonio, Texas.https://peer.asee.org/21282

[8] Shepard, T., \& Choi, J., \& Holmes, T. D., \& Carlin, B. W. (2015, June), The Effect of Project Constraints on First Year Microcontroller Projects. Paper presented at 2015 ASEE Annual Conference and Exposition, Seattle, Washington. 10.18260/p.24860

[9] Susan Freeman, Richard Whalen, Courtney Pfluger, Bala Maheswaran, Mark Sivak, Josh Hertz. (2016), The Cornerstone Course: Projects and Progress, FYEE Annual Conference the Ohio State University Columbus, Ohio.

[10] Swenson, J., Schnedeker, M., Coppola, S., and Madariaga, L. (2015) Examining the Influence of an Ill- and Well-defined Problems in a First-Year Engineering Design Course. In Proceedings of the American Society of Engineering Education Annual Conference and Exposition, Seattle, Washington.

[11] Meyers, K., \& Conner, B. P., \& Morgan, A. S. (2016, June), 3-D Printing in a First-Year Engineering Design Project Paper presenter at 2016 ASEE Annual Conference and Exposition, New Orleans, Louisiana. 10.18260/p.26244 
[12] David Hall, Hishm Hegab, and James Nelson. Living with the Lab - A freshman curriculum to boost hands-on learning student confidence and innovation. In 2008 Frontiers of Education, Saratoga Springs, NY, October 22-28 2008. ASEE/IEEE.

[13] David Hall, Stan Conk, James Nelson, and Patricia Brackin. Facilitating lifelong learning skills through a first-year engineering curriculum. In 2009 Annual Conference \& Exposition, Austin, TX, 2009. American Society for Engineering Education. paper no AC 2010-1268.

[14] Leah H. Jamieson and Jack R. Lohmann, Creating a culture for scholarly and systematic innovation in engineering education. American Society for Engineering Education, Washington, DC, June 2009. 


\section{APPENDIX Survey of Students}

\section{Likert-Scale Questions}

Strongly Agree/Disagree/Neutral/Agree/Strongly Agree

Course and Project Related Questions

1. In this course we gain an understanding of the design process.

2. In the course project we gained an understanding of contemporary engineering practice.

3. I have enhanced my ability to design a system, component, or process to meet desired needs.

4. I intend to practice, conduct research in, or teach engineering for at least 3 years after graduation.

5. Overall, this class has increased my interest in engineering or computer science.

6. The hands-on experience in this class has improved my confidence in my ability to succeed in engineering or computer science.

7. The manufacturing and fabrication experience in this class has increased my motivation for school work.

8. The in-class exercises, such as programming, working with breadboard circuits, fabrication has decreased my motivation to study math, physics and chemistry.

9. I am happy with my team this semester.

10. I was dissatisfied with my project selection this semester.

11. I plan to continue working on the product developed in class.

12. I am proud of the product I created in class.

13. I am interested in creating another product in the future.

14. I am interested in working on a team to change an existing product.

15. I feel more equipped to solve problems when I'm stuck.

\section{Project Preference Questions}

16. Rapid Assembly and Design Challenge projects (RAD) [free-choice OEP] are openended projects where students design and build a prototype for an innovative device from a project idea that they develop. These students are given a small budget and a mentor to help them plan out the project and learn the skills that they need to create a working prototype.

a. Given the description above, I would have liked to participate in a RAD project during the duration of this course.

b. Considering the knowledge I had coming into this course without additional resources I feel like I would have been able to complete a RAD project.

c. With the additional resources provided by the course (A personalized mentor, a project stipend, teaching assistants, manual, coding guides, workshops, etc.) I feel like I would have been reasonably able to complete a RAD project.

17. Advanced Guided Projects (AGP) [Prompt-based OEP] are projects whose initial ideas come from faculty within the course and from faculty around Tandon, these ideas are more focused and the final prototype has a clearer solution than RAD projects. These 
groups are also given a small budget and a mentor to lead them throughout the project and connect them to resources.

a. Given the description above, I would have liked to participate in a AGP project during the duration of this course.

b. Considering the knowledge I had coming into this course without additional resources I feel like I would have been able to complete a AGP.

c. With the additional resources provided by the course (A personalized mentor, a project stipend, teaching assistants, manual, coding guides, workshops, etc.) I feel like I would have been reasonably able to complete an AGP.

18. Pre-defined projects are our standard course offerings including the Lego robotics courses, the nano-robotics challenge, and the NYU-Housing and Innovation in Revit challenge. These projects have known goals and outcomes.

a. Given the description above, I would have liked to participate in a pre-defined project during the duration of this course.

b. Considering the knowledge I had coming into this course without additional resources I feel like I would have been able to complete a pre-defined project.

c. With the additional resources provided by the course (Teaching assistants, manual, coding guides, workshops, etc.) I feel like I would have been reasonably able to complete a pre-defined project.

\section{Special Questions}

19. What project did you participate in?

a. Rapid Assembly and Design (RAD) [Free-choice OEP]

b. Advanced Guided Project (AGP) [Prompt-based OEP]

c. Pre-defined Project (Lego Robot)

d. Pre-defined Project (NRC)

e. Pre-defined Project (HIR)

20. Given the descriptions of RAD [free-choice OEP], AGP [prompt-based OEP], and Predefined Projects in the previous questions, please rank them in order of preference of the project you would have liked to participate in. A modified description is listed next to the project name

21. Given the three available options (RAD, AGP, and Pre-defined Projects), describe which project(s) you would prefer and why.

22. Which part of the project took the most time and effort?
a. Brainstorming
b. Algorithm
c. Prototyping
d. Programming
e. CAD and 3D Modeling
f. Measuring and Testing

23. Of the twenty-three design activities below, please put a check mark next to the SIX MOST IMPORTANT.
a. Abstracting 

b. Brainstorming
c. Building
d. Communicating
e. Decomposing
f. Evaluating
g. Generating alternatives
h. Goal setting
i. Identifying constraints
j. Imaging
k. Iterating
1. Making decisions
m. Making trade-offs
n. Modeling
o. Planning
p. Prototyping
q. Seeking information
r. Sketching Synthesizing
s. Testing
t. Understanding the problem
u. Visualizing
v. I prefer not to answer

24 . What did you struggle with the most on your project?

25 . What did you enjoy the most about your project (what shouldn't change)?

26. What tools and resources would you have wanted for your project?

27. What additional instruction would be helpful for your design project?

28. Do you have any other recommendations for your project? 